\title{
Remediasi Miskonsepsi Mahasiswa Calon Guru Fisika Pada Materi Mekanika Melalui Penerapan Model pembelajaran Inkuiri dan Creative Problem Solving
}

\author{
Iqbal Nurhidayat ${ }^{1}$, Nana $^{2}$ \\ ${ }^{1}$ Mahasiswa Program Studi Pendidikan Fisika, Universitas Siliwangi \\ ${ }^{2}$ Dosen Program Studi Pendidikan Fisika, Universitas Siliwangi \\ *E-mail korespondensi : Iqbalnurhidayat1998@ gmail.com
}

\begin{abstract}
Abstrak: Penelitian ini dilakukan untuk mengidentifikasi miskonsepsi mahasiswa pendidikan Fisika yang berkaitan dengan materi "Mekanika" dengan melalui penerapan model inkuiri dan Creative Problem Solving (CPS). Adapun penelitian ini dilakukan dengan mengguankan metode studi pustaka. Sejalan dengan hal itu, penelitian ini dilakukan pada mahasiswa jurusan pendidikan Fisika. Penelitian ini bertujuan untuk (1) mengetahui tingkatan miskonsepsi yang terjadi pada mahasiswa Jurusan Pendidikan Fisika (2) mengetahui efektivitas Model inkuiri dan model Creative Problem Solving untuk mengurangi tingkatan miskonsepsi yang terjadi pada mahasiswa pendidikan fisika.
\end{abstract}

Kata Kunci : Remediasi, Miskonsepsi, Model inkuiri, Model Creative Problem Solving, Mekanika

Abstract: This research was conducted to identify misconceptions of students of Physics education related to the material "Mechanics" by applying the Inquiry model and Creative Problem Solving (CPS) model. The research was conducted by using the literature study method. In line with this, this research was conducted on students majoring in Physics education. This study aims to (1) determine the level of misconceptions that occur in students of the Department of Physics Education (2) determine the effectiveness of the Creative Problem Solving Model to reduce the level of misconceptions that occur in physics education students.

Keywords: Remediation, Misconception, inquiry model, Creative Problem Solving (CPS) model, Mechanic

\section{PENDAHULUAN}

Dalam proses belajar mengajar akan terjadi proses interaksi antara guru dan siswa dimana guru menyampaikan informasi kepada siswa berupa transfer konsep melalui ceramah. Dan siswa menerima apa adanya tanpa ada filter. Dalam hal ini guru mengikuti aliran Behaviourisme yang menganggap otak siswa seperti buku kosong yang siap ditulisi sesuai dengan kehendaknya. Tetapi fakta menunjukkan sebaliknya otak siswa sudah penuh dengan pengalaman dan pengetahuan yang berhubungan dengan pelajaran.

Beberapa keadaan dalam perkuliahan fisika dijumpai penguasaan konsep mahasiswa calon guru fisika salah satunya dalam konsep mekanika masih terjadi. Walaupun mahasiswa dapat mengingat fakta-fakta, proses-proses, prinsip-prinsip, dan rumus-rumus, mereka hanya memahami 
sedikit konsep-konsep Mekanika. Pada umumnya mereka memiliki sedikit kemampuan untuk menghubungkan konsep yang mereka pelajari dari buku ajar maupun dengan lingkungannya. Taufiq, et al. (2010). Melaporkan hasil identifikasi konsepsi mahasiswa yang menunjukkan tingginya kesalahan konsep yang dialami oleh mahasiswa calon guru fisika, dan letak kesalahan nya tidak pada perhitungan matematika saja namun juga mahasiswa mengalami miskonsepsi berkaitan dengan konsep fisikanya dengan tingkatan yang berbeda-beda.

Menurut (Nana, 2018) "Tidak dapat dipungkiri banyak sekali hambatan yang dilalui dalam mengaktifkan daya nalar dan kreativitas siswa dikarenakan tingkat intelengensi yang berbedabeda. Tentu saja hal tersebut menjadi tolak ukur dalam pembelajaran di kelas maupun di luar kelas." Berdasarkan hal itu maka diperlukannya pengaplikasian sebuah model yang bisa mengembangkan kreativitas siswa dalam proses pembelajaran salah satunya adalah model Creative Problem Solving.

"Seorang guru harus melihat siswa bukan seperti lembaran kosong atau tabula rasa, mereka sudah membawa pengetahuan awal, pengetahuan yang mereka punyai adalah dasar untuk membangun pengetahuan selanjutnya. Dengan pengalaman dan pengetahuan yang telah dimiliki siswa, akan terbentuk suatu intuisi dan teori siswa yang belum tentu intuisi dan teori tersebut benar. Intuisi ini membentuk suatu prakonsep yang sederhana sampai yang komplek, cukup logis, konsisten serta sulit untuk di reduksi." (Nana, 2018)

Euwe van den Berg (1991) menyatakan, bahwa salah dalam satu bagian dari jaringan konsep Fisika dapat mempengaruhi seluruh jaringan, sehingga seseorang tidak dapat mengerti hakikat suatu konsep Fisika dan penerapannya dalam kehidupan sehari- hari. Salah konsepsi Fisika sulit sekali diubah dan tidak dapat dihilangkan dengan metode ceramah, walaupun metode ini dilaksanakan dalam pembelajaran dengan sebaik-baiknya. Ini berarti, salah konsepsi Fisika merupakan "penyakit" yang seharusnya segera diketahui obatnya dan segera diketahui bagaimana cara mengatasinya.

"Miskonsepsi mencakup: 1) pengertian yang tidak akurat tentang konsep, 2) penggunaan konsep yang salah, 3) klasifikasi contoh-contoh yang salah tentang penerapan konsep, 4) pemaknaan konsep yang berbeda, 5) kekacauan konsep-konsep yang berbeda, dan 6) hubungan hierarkis konsep-konsep yang tidak benar" (Suparno, 2005: 4).

\section{METODE PENELITIAN}

Metode yang digunakan dalam penelitian ini adalah studi kepustakaan. Penelitian ini melihat hasil dari penelitian yang telah dilakukan oleh Ahmad Abu Hamid (2005) yang melakukan penelitian di berbagai Universitas yang ada di Indonesia yang terdapat jurusan pendidikan Fisika, Kemudian akan Dianalisis Berdasarkan Penelitian yang dilakukan oleh Aulia Radif, dkk (2016) dalam pengaruh dari Model Pembelajaran Inkuiri dan Model Creative Problem Solving terhadap mata pelajaran Mekanika kelas X Teknik permesinan di SMK, populasi dari penelitian adalah seluruh siswa kelas $\mathrm{X}$ teknik permesinan dan sampel penelitian adalah kelas X TPMI 1 dan X TPMI 2. Data dikumpulkan untuk dianalisis kemudian disajikan dalam hasil dan pembahasan agar dapat dibuat kesimpulan. 


\section{HASIL DAN PEMBAHASAN}

Dalam penelitian yang dilakukan Ahmad Abu Hamid (2005), Pada bagian ini akan disajikan proporsi jawaban mahasiswa yang mampu menjawab benar dan lengkap terhadap butir-butir tes yang diujikan. Proporsi jawaban rerata yang benar dan lengkap (taraf serap) adalah perbandingan antara rerata sekor jawaban yang benar dan lengkap dengan jumlah responden dikalikan dengan $100 \%$. Seperti telah diungkap di bagian depan, bahwa profil salah konsepsi dalam penelitian ini akan mengungkap taraf serap mahasiswa yang berkaitan dengan pokok uji Mekanika seperti tabel 1 berikut.

Tabel 1: Pokok Uji dan Konsep yang Dikembangkan

\begin{tabular}{|c|l|l|}
\hline No. & \multicolumn{1}{|c|}{ Pokok yang Diujikan } & \multicolumn{1}{c|}{ Konsep yang dikembangkan } \\
\hline 1 & Mekanika & a. Gerak \\
& & b. Gaya \\
& & c. Energi dan Momentum \\
\hline
\end{tabular}

Hasil taraf serap (dalam prosen) atau salah konsespsi Fisika Mahasiswa Pendidikan Fisika pada masing-masing pokok uji dan konsep yang dikembangkan adalah seperti tabel 2 berikut.

Tabel 2 : Taraf serap Mahasiswa pada Masing-Masing konsep yang Dikembangkan

\begin{tabular}{|c|c|c|c|c|c|c|c|c|c|c|}
\hline \multirow[t]{2}{*}{ No } & \multirow{2}{*}{$\begin{array}{c}\text { Konsep yang } \\
\text { dikembangkan }\end{array}$} & \multicolumn{9}{|c|}{ Taraf Serap Lembaga } \\
\hline & & $\begin{array}{c}\mathrm{A} \\
(\%)\end{array}$ & $\begin{array}{c}\mathrm{B} \\
(\%)\end{array}$ & $\begin{array}{c}\mathrm{C} \\
(\%)\end{array}$ & $\begin{array}{c}\mathrm{D} \\
(\%)\end{array}$ & $\begin{array}{c}\mathrm{E} \\
(\%)\end{array}$ & $\begin{array}{c}\mathrm{F} \\
(\%)\end{array}$ & $\begin{array}{c}\mathrm{G} \\
(\%)\end{array}$ & $\begin{array}{c}\mathrm{H} \\
(\%)\end{array}$ & $\begin{array}{c}\mathrm{I} \\
(\%)\end{array}$ \\
\hline \multirow[t]{7}{*}{1} & Mekanika & & & & & & & & & \\
\hline & a. Gerak & 48,5 & 30,2 & 39,1 & 7,62 & 39,0 & 14,2 & 22,2 & 38,0 & 27,7 \\
\hline & b. Gaya & 7 & 9 & 3 & 3,33 & 5 & 9 & 9 & 0 & 7 \\
\hline & c. Energi dan & 60,0 & 21,0 & 11,9 & 0,05 & 43,3 & 18,0 & 23,1 & 23,1 & 23,7 \\
\hline & Momentum & 0 & 0 & 6 & & 3 & 0 & 7 & 1 & 1 \\
\hline & & 23,7 & 13,0 & 15,3 & & 23,3 & 6,94 & 7,00 & 22,1 & 15,8 \\
\hline & & 5 & 0 & 0 & & 3 & & & 7 & 5 \\
\hline
\end{tabular}

Keterangan Tabel 2:

A : Universitas Kristen Satya Wacana

B : Universitas negeri Sebelas Maret

C : Universitas negeri Semarang

D : Universitas Muhammadiyah Purworejo

E : Universitas Sanata Dharma

F : Universitas Sarjana Wiyata Taman Siswa

G : Universitas Ahmad Dahlan

$\mathrm{H}$ : Universitas Negeri Yogyakarta, dan

I : Total / Keseluruhan. 
Tabel 2 memberikan gambaran, bahwa pokok uji yang diberikan kepada mahasiswa memuat beberapa konsep yang berkaitan dengan Mekanika,. Konsep-konsep yang dikembangkan untuk menjaring salah konsepsi di kalangan mahasiswa ini sengaja diambil pokok permasalahan yang sering ditafsirkan salah. Oleh sebab itu, proporsi taraf serap (dalam \%) benar-benar menunjukkan salah konsepsi Fisika. Semakin besar proporsi taraf serap semakin kecil salah konsepsinya, demikian sebaliknya.

Tabel 3 Uji Mannova Model Pembelajaran Terhadap Hasil Belajar Kognitif Dan Kemampuan Berpikir Kreatif

Multivariate test ${ }^{\mathfrak{c}}$

\begin{tabular}{lllllll}
\hline Effect & & Value & F & $\begin{array}{l}\text { Hypotesis } \\
\text { df }\end{array}$ & Error df & Sig. \\
\hline Intercept & Pillai's Trade & .961 & $500.018^{\mathrm{a}}$ & 2.000 & 41.000 & .000 \\
& Wilks' Lambda & .0 .39 & $500.018^{\mathrm{a}}$ & 2.000 & 41.000 & .000 \\
& Hotrlling' Trace & 24.391 & $500.018^{\mathrm{a}}$ & 2.000 & 41.000 & .000 \\
& Roys's Largest & 24.391 & $500.018^{\mathrm{a}}$ & 2.000 & 41.000 & .000 \\
& Root & & & & &
\end{tabular}

\section{Multivariate test $\mathbf{c}^{\mathrm{c}}$}

\begin{tabular}{lllllll}
\hline Effect & & Value & F & $\begin{array}{l}\text { Hypotesis } \\
\text { df }\end{array}$ & Error df & Sig. \\
\hline Intercept & Pillai's Trade & .511 & 7.201 & 4.000 & 84.000 & .000 \\
& Wilks' Lambda & .549 & 7.173 & 4.000 & 82.000 & .000 \\
& Hotrlling' Trace & .714 & 7.139 & 4.000 & 80.000 & .000 \\
& Roys's Largest & .495 & 10.394 & 2.000 & 42.000 & .000 \\
& Root & & & & &
\end{tabular}

\footnotetext{
a. Exact statistic

b. The statistic is an upper bound on $\mathrm{F}$ that yields a lower bound on the significance level.

c. Design: Intercept + Model_pembelajaran

Berdasarkan Penelitian Aulia Radif, dkk (2016) pada tabel 3, yang melakukan uji hipetesis menggunakan Teknik multivariat (Mannova) berdasarkan perbedaan centroid tiga kelompok dilihat dari nilai pillai's Trade, Wilks' Lambda, Hotrlling' Trace dan Roys's Largest Root. Keempat nilai uji statistika tersebut ditransformasikan ke dalam uji F menunjukan uji F signifikan pada $\propto=5 \%$, hal ini berarti model pembelajaran berpengaruh terhadap hasil belajar kognitif dan kemampuan berpikir kreatif.
} 
Tabel 4 Tabel test of between-Subjects effects

Test of Between-Subject Effect

\begin{tabular}{|c|c|c|c|c|c|c|}
\hline Source & Dependent variable & $\begin{array}{l}\text { Type III } \\
\text { Sum of } \\
\text { squares }\end{array}$ & $\overline{\mathrm{df}}$ & $\begin{array}{l}\text { Mean } \\
\text { square }\end{array}$ & $\mathrm{F}$ & Sig. \\
\hline & Hasil Belajar & $2680.000^{\mathrm{a}}$ & 2 & 1340.000 & 6.091 & .005 \\
\hline Correcte & kognitif & & & & & \\
\hline d Model & $\begin{array}{l}\text { Kemampuan } \\
\text { berpikir kreatif }\end{array}$ & $2641.111^{\mathrm{b}}$ & 2 & 1320.556 & 9.846 & .000 \\
\hline \multirow[t]{4}{*}{ Intercept } & Hasil Belajar & 151380.00 & 1 & 151380.000 & 688.091 & .000 \\
\hline & kognitif & 0 & 1 & 105575556 & & $0 \cap 0$ \\
\hline & hernikir kreatif & 135575.55 & & & & \\
\hline & & 6 & & & & \\
\hline \multirow{4}{*}{$\begin{array}{l}\text { Model } \\
\text { Pembelaj } \\
\text { aran }\end{array}$} & Hasil Belajar & 2680.000 & 2 & 134.000 & 6.091 & .005 \\
\hline & kognitif & & & & & \\
\hline & Kemampuan & 26410111 & 2 & 1320.556 & 9.864 & .000 \\
\hline & berpikir kreatif & & & & & \\
\hline \multirow[t]{3}{*}{ Error } & $\begin{array}{l}\text { Hasil Belajar } \\
\text { kognitif }\end{array}$ & 9240.000 & 42 & 220.000 & & \\
\hline & Kemampuan & 5633.333 & 42 & 134.127 & & \\
\hline & berpikir kreatif & & & & & \\
\hline \multirow[t]{5}{*}{ Total } & Hasil Belajar & 163300.00 & 45 & & & \\
\hline & kognitif & 0 & & & & \\
\hline & Кетатриап & & 45 & & & \\
\hline & berpikir kreatif & 143850.00 & & & & \\
\hline & & 0 & & & & \\
\hline \multirow[t]{3}{*}{$\begin{array}{l}\text { Correcte } \\
\text { d Total }\end{array}$} & $\begin{array}{l}\text { Hasil Belajar } \\
\text { koonitif }\end{array}$ & 11920.000 & 44 & & & \\
\hline & Kemampuan & 8274.444 & 44 & & & \\
\hline & berpikir kreatif & & & & & \\
\hline
\end{tabular}


a. R. Squared $=.225$ (Adjusted R Squared $=.118$ )

b. R. Squared $=.319$ (Adjusted R Squared $=.287$ )

Berdasarkan tabel 4 yang menyajikan uji univariat yang menunjukan hasil perhitungan perbedaan antara model pembelajaran inkuiri dan CPS menunjukan bahwa nilai signifikasi kurang dari 0,05 yakni sebesar 0.000. hal tersebut berarti hipotesis nol ditolak dan hipotesis penelitian diterima, Jadi ada perbedaan kemampuan berpikir kreatif seiswa kelas X pada mata pelajaran Mekanika Teknik antara model pembelajaran inkuiri dan CPS.

Berdasarkan Tabel dapat dilihat bahwa terjadi hasil pembelajaran pada siswa kelas X pada mata pelajaran Mekanika Teknik antara model pembelajaran inkuiri, dan CPS. Model pembelajaran inkuiri dapat meningkatkan hasil belajar kognitif yang lebih baik dibandingkan dengan model CPS. Namun, dalam peningkatannya pun tidak terlalu signifikan jika dibbandingkan denganmodel pembelajaran CPS.

\section{PENUTUP}

Secara umum dapat disimpulkan hal-hal sebagai berikut :

1. Miskonsepsi fisika di kalangan mahasiswa Pendidikan fisika di LPTK masih tinggi, seperti dalam bidang Mekanika yang meliputi konsepsi gerak, gaya energi, dan momentum. Oleh sebab itu, perlu penanganan yang serius dalam pembelajaran Fisika di jurusan Pendidikan Fisika, melalui program-program khusus, misalnya remediasi.

2. Terdapat hubungan yang signifikan hasil belajar kognitif siswa kelas $\mathrm{X}$ pada mata pelajaran Mekanika Teknik, tedapat perbedaan yang signifikan hasil belajar kognitif siswa kelas X SMK pada mata pelajaran Mekanika Teknik antara model inkuiri dan Creative Problem Solving.

3. Dari kedua penelitian yang dilakukan oleh Ahmad Abu Hamid (2005) dan Aulia Radif, dkk (2016) dapat ditarik kesimpulan bahwa model inkuiri dan model Creative Problem Solving bisa menjadi solusi dalam meminimalisir terjadinya miskonsepsi pada mahasiswa atau siswa dalam pembelajaran Fisika khususnya pada materi "Mekanika".

\section{DAFTAR PUSTAKA}

Euwe van den Berg (ED.), (1991), Miskonsepsi Fisika dan Remediasi, Salatiga: UKSW. Hamid, Ahmad Abu. (2005). Salah Konsep Fisika dan Faktor-Faktor Yang Mempengaruhinya. Yogyakarta. Jurdik Fisika FMIPA UNY.

Nana. (2018). Penerapan Model Creative Problem Solving Berbasis Blog Sebagai Inovasi Pembelajaran Di Sekolah Menengah Atas Dalam Pembelajaran Fisika. Tasikmalaya. Universitas siliwangi

Nana. (2018). Penggunaan Pendekatan Konflik Kognitif Untuk Remediasi Miskonsepsi Pembelajaran Suhu Dan Kalor. Tasikmalaya. Universitas Siliwangi.

Radif, Aulia. Dkk. (2016). Pengaruh Penggunaan Model Pembelajaran Inkuiri Dan Model Creative Problem Solving (Cps) Terhadap Hasil Belajar Kognitif Dan Kemampuan Berpikir Kreatif Mata Pelajaran Mekanika Teknik Siswa Kelas X Smk. Malang. Universitas Negeri Malang. 
Suparno, P. (2005). Miskonsepsi dan Perubahan Konsep Pendidikan Fisika. Jakarta. Gramedia. Taufiq, M. et.al., (2010). Student's Sience Misconceptions Cornering The State Changes of Water and Their Remidiation Using Three Different Learning Models In Elementary School. Prosiding Seminar Nasional Fisika Unnes 2010. Universitas Negeri Semarang. 